\title{
OS PRINCÍPIOS DO DIREITO AMBIENTAL E A DOUTRINA DA ENCÍCLICA PAPAL LAUDATO SÍ'
}

\author{
THE PRINCIPLES OF ENVIRONMENTAL LAW AND THE \\ DOCTRINE OF THE PAPAL ENCYCLIC LAUDATO SÍ'
}

Clóvis Reis ${ }^{1}$

Resumo: As encíclicas papais são documentos que exercem influência na comunidade internacional, pois extrapolam o debate que a Igreja Católica promove internamente a respeito de questões de fé. Um exemplo é a encíclica Laudato Si' [Louvado sejas, em português] (2015), a chamada Carta Verde, a qual versa sobre meio ambiente e desenvolvimento sustentável, tema que integra a agenda política, econômica e social do mundo contemporâneo. Neste contexto, o presente trabalho analisa a relação entre os princípios do Direito Ambiental e as orientações doutrinárias de Laudato Si'. Os dados são apresentados e discutidos através da técnica de análise de conteúdo, a qual relaciona as características de um texto à fonte produtora da mensagem. Os resultados da pesquisa apontam as contribuições da encíclica para a promoção de um modelo de desenvolvimento comprometido com o meio ambiente e a qualidade de vida.

Palavras-chave: Direito Ambiental; Laudato Si’; Encíclica papal.

Abstract: Papal encyclicals are documents that exert influence in the international community, as they go beyond the debate that the Catholic Church promotes internally regarding issues of faith. An example is the encyclical Laudato Si '[Louvado sejas, in Portuguese] (2015), the so-called Green Letter, which deals with the environment and sustainable development, a theme that integrates the political, economic, and social agenda of the contemporary world. In this context, the present work analyzes the relationship between the principles of Environmental Law and the doctrinal guidelines of Laudato $\mathrm{Si}$ '. The research employs the content analysis technique to present and discuss the data. The content analysis relates the characteristics of a text to the source producing the message. The results point out the contributions of the encyclical to the promotion of a development model committed to the environment and the quality of life.

Keywords: Environmental Law; Laudato Si'; Papal encyclical.

\footnotetext{
1 Professor do PPGD-Programa de Pós-Graduação em Direito e do PPGDR-Programa de Pós-Graduação em Desenvolvimento Regional da FURB-Universidade Regional de Blumenau; Doutor em Comunicação; Bacharel em Direito e em Jornalismo; Licenciado em Letras. Email: professorclovisreis@ gmail.com.
} 


\section{INTRODUÇÃO}

As encíclicas papais são documentos que exercem influência na comunidade internacional, pois extrapolam o debate que a Igreja Católica promove internamente a respeito de questões de fé. Entre as circulares que produziram repercussão na ordem mundial, incluem-se as denominadas Rerum Novarum, sobre o direito dos trabalhadores; Non abbiamo bisogno, sobre o fascismo; Mit brennender Sorge, sobre o nacional-socialismo, Divinis Redemptoris, sobre o comunismo, e Pacem in Terris, sobre os direitos humanos.

No recente pontificado, o papa Francisco recolhe em sua pregação temas que compõem a agenda política, econômica e social do mundo contemporâneo. Um exemplo é a publicação da encíclica Laudato Si' [Louvado sejas, em português] (A SANTA SÉ, 2015), primeiro documento pontifício inteiramente dedicado ao cuidado da Terra. A chamada Carta Verde atribui um estatuto supranacional a um tema que diversos países e organizações tentam fixar entre as pautas internacionais, do que são referência as cúpulas da ONU sobre mudança climática.

A rigor, Laudato $S i$ ' não traz novidades em termos doutrinários, mas inova na medida em que cobra responsabilidades sobre o aquecimento global e o futuro do planeta e incorpora uma abordagem de natureza política na pregação religiosa (POU-AMÉRIGO, 2018). Como consequência causou forte repercussão entre os líderes mundiais e na opinião pública.

Neste contexto, o presente trabalho se propõe a analisar a relação entre os princípios do Direito Ambiental no Brasil e as orientações doutrinárias da encíclica papal Laudato Si', ponderando suas contribuições para a preservação do meio ambiente e a promoção da qualidade de vida. Para isso, busca identificar os princípios do Direito Ambiental, verificar as orientações doutrinárias da encíclica papal e refletir sobre a relação entre o Direito Ambiental e a Laudato Si'.

Desde a perspectiva da metodologia científica, classifica-se o presente trabalho como uma pesquisa básica (do ponto de vista da sua natureza), qualitativa (quanto à abordagem do problema) e descritiva (quanto à realização dos objetivos). Os procedimentos adotados para a coleta de dados são a revisão bibliográfica e a leitura de documentos. Autores como Machado (2009), Beltrão (2011), Fiorillo (2011), Silveira (2012) e Sirvinskas (2013) revelam-se fundamentais para a constituição do marco teórico da investigação.

No caso concreto da encíclica Laudato Si', os dados são analisados a partir de uma técnica denominada análise de conteúdo, a qual permite estabelecer a relação entre os 
princípios do Direito Ambiental e as orientações doutrinárias da circular papal. Bardin (1977) diz que o procedimento possibilita analisar a causa a partir dos efeitos, relacionando as características de um texto à fonte produtora da mensagem. Em certa medida, o emprego de tal procedimento representa uma contribuição metodológica do presente trabalho à pesquisa na área do Direito, uma vez que a análise de conteúdo não se inscreve entre os métodos clássicos de interpretação de textos neste campo do conhecimento.

Os resultados da análise de conteúdo são apresentados a partir do método indutivo. Os dados aqui apresentados integram um trabalho mais amplo e constituem uma aproximação preliminar ao tema, buscando contribuir para a realização de novas pesquisas na área e, assim, favorecer as reflexões sobre as mudanças climáticas, a preservação do planeta e a manutenção da qualidade de vida para as atuais e as futuras gerações.

\section{ENCÍCLICA LAUDATO SI,}

$\mathrm{Na}$ organização da Igreja Católica, alguns textos são considerados fundamentais, tais como a Bíblia, o Catecismo, o Concílio Vaticano II e o Código de Direito Canônico. Nesse contexto, um conjunto de produções em particular integra uma categoria denominada Documentos do Magistério, os quais incluem as publicações assinadas pelo papa, os trabalhos firmados pela Cúria Romana e os pronunciamentos dos bispos.

Os textos de origem papal são chamados de documentos pontifícios e contemplam produções que recebem nomes diversos. A classificação leva em conta tanto o conteúdo quanto a hierarquia das publicações. As principais são a Bula (o mais importante de todos os títulos), o Breve (Bula menos longa), o Rescrito (resposta a uma pergunta ou solicitação), o Motu Proprio (carta de iniciativa do próprio papa) e a Encíclica (carta circular que orienta os fiéis). (AQUINO, 2016)

As encíclicas papais constituem um modo habitual de comunicação da Igreja Católica. Geralmente são escritas em latim, acompanhadas de tradução, e publicadas entre os Atos da Sé Católica. Na maioria das vezes, o título deriva das palavras que o autor emprega na abertura do documento.

No século XVIII, sob o pontificado de Bento XIV (1740-1758), a encíclica atingiu o estatuto de que desfruta na atualidade, ganhando notoriedade a partir da ascensão do papa Gregório XVI (1831-1846). O site do Vaticano na internet (A SANTA SÉ, s/d) disponibiliza o acesso a um total de 222 encíclicas, publicadas por nove papas, a partir de 1878. Não obstante, Aquino (2016) afirma que a primeira encíclica que se conhece foi escrita pelo papa Clemente I, cujo pontificado se estendeu do ano 88 a 97. A agência de notícias católicas 
Ecclesia informa a existência de um total de 298 encíclicas publicadas na história da Igreja Católica (ECCLESIA, 2015).

De acordo com o site do Vaticano (A SANTA SÉ, s/d), o papa Leão XIII é o mais prolífico dos autores, com a soma de 86 publicações ao longo do seu ministério (1878-1903). A seguir aparece o papa Pio XII, com 41 encíclicas escritas durante seu pontificado (19391958).

Penúltimo papa, Bento XVI, publicou as encíclicas Deus caritas est (2005), Spe Salvi (2007) e Caritas in veritate (2009), no transcurso dos quase oito anos de pontificado. Segundo especialistas, ele também teve participação direta na elaboração de Lumen Fidei (2013), tornada pública após a sua renúncia e já sob os auspícios do sucessor, o papa Francisco (ESTADÃO, 2013).

Francisco elegeu-se sumo pontífice da Igreja Católica em 13 de março de 2013, sucedendo Bento XVI, que renunciou ao cargo no mês anterior. Ele é o $266^{\circ}$ papa da história, o primeiro latino-americano e o primeiro que adotou o nome de São Francisco.

Entre os principais documentos do pontificado do atual papa estão a encíclica Lumen Fidei (A luz da Fé), na qual Francisco recolhe reflexões de Bento XVI, a exortação apostólica Evangelii Gaudium (A Alegria do Evangelho) e a encíclica Laudato Si' (Louvado Sejas).

Com efeito, Laudato Si' veio a lume a 24 de maio de 2015, no terceiro ano do pontificado do papa Francisco. O site do Vaticano (2015) disponibiliza o documento online e na versão em pdf nos idiomas árabe, chinês, francês, inglês, italiano, latim, polonês, português, russo, espanhol e alemão.

Além disso, empresas ligadas à Igreja Católica lançaram versões impressas da encíclica. No Brasil, as editoras Paulus e Loyola publicaram uma edição conjunta da circular na série Documentos do Magistério, que engloba encíclicas, exortações apostólicas, bulas e cartas apostólicas.

A encíclica tem uma introdução e seis capítulos que comportam 246 parágrafos/tópicos numerados, o último deles contendo duas orações (Oração pela nossa terra e Oração cristã com a criação). A Introdução de Laudato Si’ começa com o Cântico das Criaturas, de São Francisco de Assis, a seguir relaciona as raízes bíblicas de uma encíclica dedicada ao futuro do planeta, o legado de outros papas na abordagem do tema, e as bases científicas, filosóficas, teológicas e sociais da discussão.

No primeiro capítulo da encíclica, o papa apresenta o percurso ético e espiritual para discussão da crise ecológica, abordando temas como poluição e mudanças climáticas, a 
questão da água, a ameaça à biodiversidade, a deterioração da qualidade de vida humana e a degradação social, a desigualdade planetária, a fraqueza das reações governamentais e a diversidade de opiniões sobre a realidade.

O segundo capítulo da encíclica aborda a tradição judaico-cristã na defesa do meio ambiente, passando pelas narrações bíblicas, o mistério do universo, o destino comum dos bens e o olhar de Jesus Cristo a respeito do fenômeno. O objetivo desta parte da encíclica é promover um diálogo entre ciência e religião.

No terceiro capítulo, a encíclica trata dos sintomas e das causas da atual crise ecológica. Fundamentalmente, o capítulo aborda a criatividade e o poder da tecnologia, a globalização do paradigma tecnocrático, a crise do antropocentrismo moderno e as suas consequências.

O quarto capítulo da encíclica propõe uma reflexão sobre os diferentes elementos de uma ecologia integral, que inclua as dimensões ambiental, econômica, cultural e humana. De acordo com o documento, a visão consumista incentivada pela globalização tende a homogeneizar as culturas e a debilitar a variedade cultural.

No quinto capítulo, a encíclica apresenta as linhas de ação para uma ecologia integral, que leve a uma mudança de rumo e aponte uma saída para a espiral de autodestruição da atualidade. Laudato Si' aposta na força do diálogo para a construção de uma agenda local, nacional e internacional que estabeleça uma nova relação do homem com o meio ambiente. Além disso, defende o diálogo entre as religiões e as ciências.

O sexto e último capítulo da encíclica aborda o desafio cultural, espiritual e educativo para a superação da crise ecológica. O documento reforça a necessidade de mudança no estilo de vida, de reaproximação entre a humanidade e o ambiente e defende uma conversão ecológica a partir da experiência espiritual. A proposta parte da crítica ao consumismo obsessivo, que o papa considera reflexo do paradigma tecnoeconômico, cujo resultado produziria uma crise natural e social:

\section{DIREITO AMBIENTAL}

O desenvolvimento econômico, científico e tecnológico registrado nas últimas décadas produziu consequências globais que desafiam as previsões sobre o futuro do planeta. A população está mais rica, especialmente nos países desenvolvidos, mas o mundo como um todo encontra-se próximo de um desastre ecológico (GIDDENS, 2012, p. 152). Por sua parte, os ideais de desenvolvimento sustentável, justiça e cidadania ambientais alimentam discussões na busca de alternativas para a relação do homem com o meio ambiente. 
No Brasil, a questão ambiental adquire particular relevo porque a Constituição Federal de 1988 erigiu o direito de viver num ambiente ecologicamente equilibrado à categoria de direito humano fundamental (COLOMBO, 2005, p. 122). A sustentabilidade seria, portanto, um princípio jurídico revelador de um direito fundamental, cujo fim é a dignidade da pessoa humana (COELHO; MELLO, 2011, p. 11).

Com efeito, a Constituição Federal de 1988 é a primeira constituição brasileira que emprega a expressão “meio ambiente” (MACHADO, 2009, p. 126). As disposições a respeito do tema integram diversos títulos e capítulos, com destaque para o art. 225, cujo teor é o seguinte:

Art. 225 - Todos têm direito ao meio ambiente ecologicamente equilibrado, bem de uso comum do povo e essencial à sadia qualidade de vida, impondose ao Poder Público e à coletividade o dever de defendê-lo e preservá-lo para as presentes e futuras gerações. (BRASIL, 1988)

Referido artigo contém seis parágrafos, os quais versam sobre:

a) as incumbências do Poder Público para assegurar a efetividade do direito ao meio ambiente;

b) a necessidade de recuperação do meio ambiente degradado pela exploração de recursos minerais;

c) a obrigação de reparação e as sanções penais e administrativas no caso de condutas e atividades consideradas lesivas ao meio ambiente;

d) a inclusão da Floresta Amazônica, da Mata Atlântica, da Serra do Mar, do Pantanal Mato-Grossense e da Zona Costeira como patrimônio nacional;

e) a indisponibilidade das terras devolutas ou arrecadadas pelos Estados, por ações discriminatórias, necessárias à proteção dos ecossistemas naturais.

f) a localização das usinas que operem com reator nuclear.

Fiorillo (2011, p. 63-67) divide a análise do art. 225 da Constituição Federal em quatro partes, as quais contemplam as perspectivas que o autor considera mais significativas no dispositivo:

a) a existência de um meio ambiente ecologicamente equilibrado como um direito de todos, o qual considera, além das pessoas abarcadas pela soberania nacional (brasileiros e estrangeiros residentes no país), toda e qualquer pessoa humana; 
b) a compreensão do bem ambiental como um bem de uso comum do povo, inovação legislativa que cria um terceiro gênero de bem, insuscetível de apropriação, que não se confunde com os bens públicos ou os privados;

c) a estrutura finalística do direito ambiental como essencial à sua qualidade de vida, o qual está relacionado ao princípio da dignidade da pessoa humana e o acesso a direitos como educação, saúde, trabalho, lazer, segurança, etc.;

d) a tutela dos valores ambientais como um compromisso com as atuais e as futuras gerações.

Referida síntese corresponde à divisão proposta por Sirvinskas (2013, p. 151), que de igual modo destaca o meio ambiente ecologicamente equilibrado como um direito fundamental da pessoa humana, como um bem de uso comum do povo, como um bem difuso e essencial à sadia qualidade de vida do homem e, finalmente, como objeto de proteção do Poder Público e da coletividade para as presentes e as futuras gerações.

Machado (2009, p. 127-132) diz que a afirmação do direito ao meio ambiente atribui a tal expectativa o estatuto de direito subjetivo e de titularidade coletiva, bem de uso comum do povo, bem essencial à sadia qualidade de vida e bem ecologicamente equilibrado.

Assim, conforme Beltrão (2011, p. 63), o direito ao meio ambiente ecologicamente equilibrado, assegurado na nova ordem jurídica advinda da Constituição Federal de 1988, busca conjugar qualidade de vida com desenvolvimento econômico e social. De acordo com o autor, tal direito está associado ao direito à vida com qualidade, o que supõe um ambiente harmônico e sadio.

A jurisprudência pátria tem uma farta produção no campo do direito ambiental. Um julgado singular, citado por Machado (2009, p. 129), é a definição de meio ambiente que o ministro Celso Mello apresenta no julgamento do MS 22.164-0-SP, publicado em 17 de novembro de 1995. O documento conceitua o direito ao meio ambiente como um direito de terceira geração, que assiste a todo o gênero humano e que impõe ao Estado e à própria coletividade a obrigação de defendê-lo e preservá-lo em benefício das presentes e futuras gerações.

$\mathrm{O}$ art. 225 da Constituição Federal abriga os princípios diretores do Direito Ambiental no Brasil, desenvolvidos por uma série de autores. Num esforço de síntese, realizado a partir do estudo da doutrina, eles poderiam ser elencados do seguinte modo: direito humano à qualidade de vida, supremacia do interesse público, indisponibilidade do meio ambiente, desenvolvimento sustentado, princípio da precaução e da prevenção, princípio 
do poluidor pagador, respeito à identidade cultural, cooperação entre os povos e princípio da proibição do retrocesso.

\section{FÉ, DIREITO E ECOLOGIA}

Constituído o marco teórico e introduzido o caso de estudo, passa-se agora à análise do conteúdo da encíclica Laudato Si' e à identificação de relações entre a carta papal e os princípios do direito ambiental. Em concreto, a pesquisa considerou oito princípios expostos no quadro abaixo (coluna da esquerda), aos quais se relacionaram 120 palavras que o desenho metodológico do estudo associou ao respectivo campo semântico (coluna da direita).

\begin{tabular}{|l|l|}
\hline \multicolumn{1}{|c|}{ Categorias/dimensões } & \multicolumn{1}{c|}{ Variáveis/unidades de análise } \\
\hline Direito humano fundamental à qualidade de vida & $\begin{array}{l}\text { Bem-estar, cidadão, democracia, dignidade, direito, } \\
\text { educação, ética, geração, homem, participação, } \\
\text { pessoa, qualidade, sadio, saúde, vida. }\end{array}$ \\
\hline $\begin{array}{l}\text { Supremacia do interesse público na proteção do meio } \\
\text { ambiente }\end{array}$ & $\begin{array}{l}\text { Coletivo, comum, empresa, indivíduo, indústria, } \\
\text { interesse, mercado, particular, patrimônio, privado, } \\
\text { propriedade, proteção, público, segurança, social. }\end{array}$ \\
\hline Indisponibilidade do meio ambiente & $\begin{array}{l}\text { Administração, controle, defesa, dever, Estado, } \\
\text { estatal, Executivo, governo, intervenção, Judiciário, } \\
\text { justiça, Legislativo, planejamento, poder, política. }\end{array}$ \\
\hline Desenvolvimento sustentado & $\begin{array}{l}\text { Ambiente, biodiversidade, clima, consumo, } \\
\text { crescimento, desenvolvimento, ecologia, economia, } \\
\text { ecossistema, futuro, natureza, progresso, recursos, } \\
\text { sustentabilidade, tecnologia. }\end{array}$ \\
\hline Precaução e prevenção & $\begin{array}{l}\text { Consequências, cuidado, desastre, desmatamento, } \\
\text { devastação, efeito, equilíbrio, extinção, impacto, } \\
\text { morte, precaução, prejuízo, preservação, prevenção, } \\
\text { riscos. }\end{array}$ \\
\hline Poluidor pagador & $\begin{array}{l}\text { Crime, dano, degradação, limite, multa, notificação, } \\
\text { pagamento, pena, poluição, problema, recuperação, } \\
\text { reparação, repreensão, resíduo, responsabilidade. }\end{array}$ \\
\hline Cooperação entre os povos & $\begin{array}{l}\text { Civilização, comunidade, consciência, cultura, } \\
\text { diferença, identidade, idioma, manifestação, } \\
\text { memória, pobreza, povos, respeito, semelhança, } \\
\text { sociedade, tradição. }\end{array}$ \\
\hline $\begin{array}{l}\text { Cooperação, diálogo, fraternidade, fronteira, global, } \\
\text { igualdade, mundo, nação, país, paz, planeta, } \\
\text { solidariedade, Terra, território, universo. }\end{array}$ \\
\hline
\end{tabular}

Quadro 1 - Palavras-chave empregadas na análise

Fonte: Elaborado pelos autores

Os resultados apresentados adiante não consideram a frequência de palavras como artigos, pronomes, preposições, conjunções, numerais, advérbios, interjeições e verbos de ligação, cujo emprego poderia desviar a atenção dos vocábulos mais importantes para os 
objetivos deste estudo, isto é, os substantivos e os verbos. Por uma questão metodológica, não se incluiu entre as categorias/dimensões de análise o princípio que proíbe o retrocesso em matéria ambiental. Tal definição se exprime por um conjunto de palavras de difícil manejo linguístico, o que no presente caso representaria um risco adicional na execução do trabalho.

\section{CENTRALIDADE DA PESSOA HUMANA}

Eliminada a frequência de artigos, pronomes, preposições, conjunções, numerais, advérbios, interjeições e verbos de ligação, Laudato Si' emprega um total de 6.220 "possíveis palavras" contadas pelo aplicativo TagCrowd (http://tagcrowd.com/). Tal conjunto de palavras constitui o corpus do presente estudo.

Neste contexto, a palavra com a maior frequência de ocorrências é Deus, que aparece 158 vezes. Na sequência, entre as 20 unidades com o maior número de citações, figuram mundo (147), vida (137) e humano (118), ambiente (92), poder (83), desenvolvimento (79), terra (79), natureza (75), social (71), humana (69), criação (63), realidade (62), comum (57), pessoas (51), pobres (50), criaturas (50), coisas (49), amor (48) e humanidade (48).

A figura abaixo - elaborada com o emprego do aplicativo Word Clouds (http://wordclouds.com/) - apresenta uma nuvem das palavras com o maior número de ocorrências no texto da encíclica. O tamanho da fonte na imagem e a posição do vocábulo no desenho estão relacionados à frequência do termo no texto. Quanto maior o corpo da fonte e mais central a sua localização, mais alto é o número de ocorrências da palavra no documento em análise. 


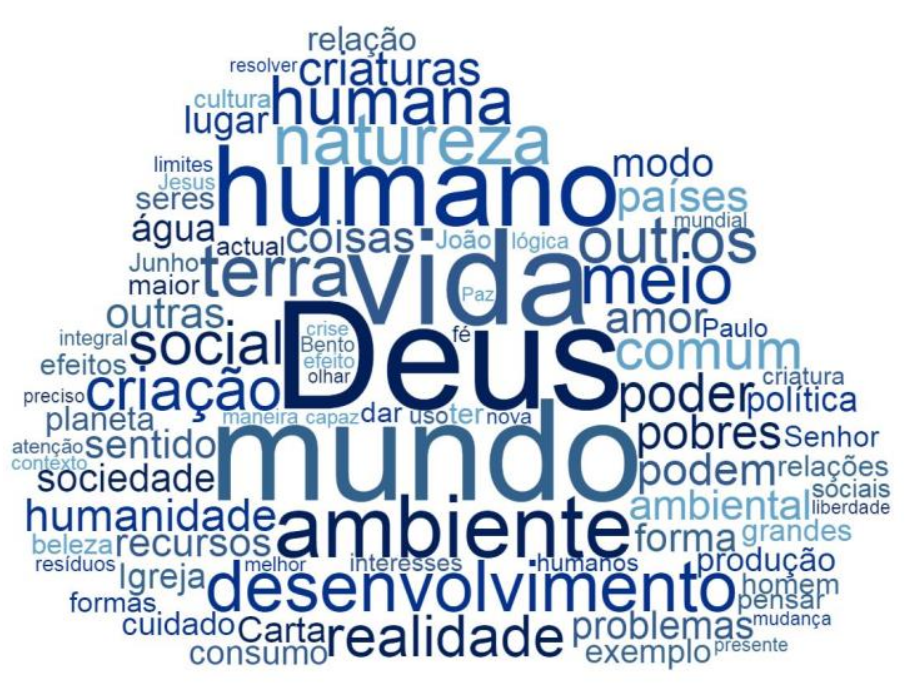

Figura 1 - Nuvem de palavras com a maior frequência de ocorrências no texto da encíclica Fonte: Elaborado pelos autores

As 120 palavras cuja frequência interessa mais diretamente ao presente trabalho (listadas no Quadro 1) somaram um total de 3.445 ocorrências, representando $55,4 \%$ do corpus do estudo. Portanto, os termos associados aos objetivos desta pesquisa - chamados de variáveis/unidades de análise - representam mais da metade dos vocábulos que compõem a encíclica papal em sua totalidade.

Na próxima tabela, apresenta-se a frequência de menção das 20 palavras mais citadas na encíclica, incluindo um agrupamento de substantivos no singular e no plural (país e países, por exemplo), no masculino e no feminino (humano e humana), além de palavras assemelhadas (clima/climático, consumo/consumismo, ecologia/ecológico, etc.).

Tabela 1 - Frequência das palavras-chave com 50 citações ou mais no texto da encíclica

\begin{tabular}{l|r}
\hline \multicolumn{1}{c|}{ Variáveis/unidades de análise } & Número de ocorrências \\
\hline Humano(a)/humanidade/homem(s) & 308 \\
\hline Mundo/mundial & 187 \\
\hline Vida/vidas & 142 \\
\hline Economia(s)/econômico(s) (a) & 106 \\
\hline Natureza/natural & 106 \\
\hline Pessoa(s)/pessoal & 100 \\
\hline Social/sociais & 98 \\
\hline Ambiente(s)/ambiental(s) & 92 \\
\hline
\end{tabular}




\begin{tabular}{l|r}
\hline Terra(s) & 84 \\
\hline Poder(es) & 83 \\
\hline Desenvolvimento & 79 \\
\hline Ecologia/ecológico & 73 \\
\hline Política(s) & 65 \\
\hline Pobre(s)/pobreza & 64 \\
\hline Comum & 57 \\
\hline Problema & 57 \\
\hline Cuidado(s)/cuidar & 55 \\
\hline Cultura(s)/cultural(s) & 54 \\
\hline Efeito(s) & 53 \\
\hline País/países & 51 \\
\hline Consumo/consumismo & 50 \\
\hline
\end{tabular}

Fonte: Elaborado pelos autores

No extremo oposto, figura um conjunto de palavras-chave com baixo índice de citação no texto. Os vocábulos administração, estatal, memória e notificação aparecem uma única vez na encíclica. Por sua vez, as palavras democracia, desmatamento, Executivo, idioma, igualdade, Judiciário, multa, planejamento, prejuízo e repreensão não são mencionados na circular da Santa Sé.

\section{APELO À SOLIDARIEDADE UNIVERSAL}

Agrupando-se as variáveis/unidades de análise de acordo com a categorias/dimensões do estudo, verifica-se que os princípios do direito ambiental mais vezes aludidos na encíclica papal são o desenvolvimento sustentado e o direito humano à qualidade de vida. Por outro lado, os conjuntos com o menor número de referências são os princípios do poluidor pagador, da precaução e da prevenção. A Tabela 2 apresenta o resultado global do estudo.

Tabela 2 - Referências aos princípios do direito ambiental no texto da encíclica

\begin{tabular}{l|r}
\multicolumn{1}{c|}{ Categorias/dimensões } & Número de ocorrências \\
\hline Direito humano fundamental à qualidade de vida & 719 \\
\hline $\begin{array}{l}\text { Supremacia do interesse público na proteção do meio } \\
\text { ambiente }\end{array}$ & 344 \\
\hline Indisponibilidade do meio ambiente & 274 \\
\hline Desenvolvimento sustentado & 763 \\
\hline Precaução e prevenção & 218 \\
\hline Poluidor pagador & 277 \\
\hline Respeito à identidade cultural & 304 \\
\hline Cooperação entre os povos & 546 \\
\hline
\end{tabular}


Se considerado que os princípios do respeito à identidade cultural e da cooperação entre os povos guardam entre si uma relação de proximidade intrínseca, evidencia-se na mostra uma abordagem textual que parte dos princípios de amplitude mais geral (sócio-filosóficos, por assim dizer) em direção aos princípios de aplicação particular ou disciplinar (como é o caso da dimensão relacionado ao poluidor-pagador, por exemplo). A constatação revela o caráter universal da mensagem do papa. Ao dirigir-se não só aos cristãos, mas a todas as pessoas do planeta, o papa invoca a solidariedade humana para a promoção de um desenvolvimento sustentável que enfrente as disfunções do mercado e assegure o respeito ao meio ambiente (VATICAN INSIDER, 2015).

\section{CRÍTICA AO MODELO DE DESENVOLVIMENTO}

A partir da leitura da encíclica papal Laudato Si', Barreto e Machado (2016, p. 335), sublinham que a relação do humano com o meio ambiente constitui um pressuposto indissociável da concepção universal dos direitos humanos e, nessa perspectiva, consideram o direito socioambiental para as presentes e as futuras gerações como um vetor interpretativo para a tomada de decisões de toda a coletividade e das nações soberanas.

Segundo Stefaniak e Stefaniak (2015, p. 119), a encíclica atribui às atividades humanas a responsabilidade pela degradação ambiental, enumera o que considera os aspectos mais graves da degradação ecológica, demonstra a ineficácia das ações gestadas internacionalmente para construir um mundo sustentável e, por fim, propõe a construção do que chamou de ecologia integral, agregando conceitos do socioambientalismo e do ecossocialismo. De acordo com Villas Boas e Nascimento (2016, p. 255), o compromisso com a ecologia integral demanda, entre outras, a responsabilidade ética, social, política, jurídica e econômica.

Com efeito, Laudato $\mathrm{Si}^{\prime}$ contempla uma diversidade de eixos temáticos, analisados a partir de diferentes perspectivas, assim identificadas: a relação entre a pobreza e a fragilidade do planeta, a convicção de que tudo está interligado no mundo, a crítica às formas de poder derivadas da tecnologia, o convite a outras maneiras de entender a economia e o progresso, o sentido humano da ecologia, a grave responsabilidade da política internacional e a proposta de um novo estilo de vida (RÁDIO VATICANO, 2015). 
A encíclica papal parte do questionamento "que mundo queremos deixar para as próximas gerações" e, sinteticamente exposta, sua mensagem se orienta pelo seguinte itinerário argumentativo (THE VATICAN ARCHIVE, 2015):

- A Terra, nossa casa comum, está em risco.

- A ameaça decorre do atual modelo de produção e consumo.

- Os problemas atingem de forma desigual os mais pobres.

- As convicções de fé oferecem ao cristão motivações para o cuidado da natureza e dos demais.

- Uma ecologia integral implica uma reflexão sobre comportamento e estilo de vida.

Para Reis e Bizawu (2015, p. 63), a circular assinada por Francisco é um "grito profético", que aborda a questão ambiental com o objetivo de "despertar a responsabilidade universal e a solidariedade planetária como valores a serem resgatados em um mundo em transformação e em crise ecológica".

Laudato $\mathrm{Si}^{\prime}$ toma a natureza como ponto de partida, passa pela justiça social e o compromisso com a sociedade para chegar ao ideal de paz interior (VATICAN INSIDER, 2015). Em nenhum momento o documento menciona explicitamente a palavra "capitalismo", mas se pode concluir que o texto constitui uma crítica ao modelo de desenvolvimento hegemônico no mundo contemporâneo, cujos pressupostos baseados na produção e no consumo/consumismo expõem ao esgotamento os recursos do planeta. Tal organização socioeconômica ameaça o direito humano fundamental ao meio ambiente ecologicamente equilibrado e deixa em suspenso o futuro da Terra, um bem comum de todos e para todos.

Para Gilardi (2016, p. 9-10), as críticas do papa ao sistema econômico revelam que o enquadramento específico do documento pontifício: “A encíclica coloca em questão a lógica produtivista do atual modelo de desenvolvimento baseado [...] na aliança entre a economia e a tecnologia e no mito do crescimento infinito".

Nessa abordagem que vai do ecológico ao social, o sumo pontífice chama a atenção para o fato de que o mercado, por si mesmo, não é garantia de desenvolvimento integral. Num momento em que os setores econômicos exercem mais poder que os próprios estados, a encíclica destaca a importância da política como caminho para a criação de novos hábitos, que levem ao decréscimo do consumo e o combate à pobreza (VATICAN INSIDER, 2015). De acordo com o papa, a cultura do desperdício, do descarte e do consumismo, praticada nos países mais ricos, é incompatível com o desenvolvimento sustentável e com o dever de preservação ambiental (LEAL, 2015, p. 164). 
Conforme Kolmes (2016, p. 14), em Laudato Si' o papa Francisco deixa clara sua opção preferencial pelos pobres, a qual exige uma ação internacional restauradora e a necessidade de combater as mudanças climáticas globais. Segundo o autor, tal ponto de partida fornece subsídios para uma tomada de decisão que reconhece as implicações do destino universal dos bens mundiais e exige uma apreciação da dignidade dos pobres.

Com efeito, a encíclica se refere a uma crise socioambiental - não haveria duas crises separadas, uma ambiental e outra social - cujo enfrentamento envolve o cuidado com a natureza e o combate à exclusão. A mudança no "estilo de vida" (expressão várias vezes utilizada ao longo do texto como referência ao atual paradigma de desenvolvimento) passa, por um lado, por uma conversão coletiva e, por outro, por uma realização pessoal orientada pela moderação (NATIONAL CATHOLIC REPORTER, 2015).

Francisco fala explicitamente em governança global/governança ambiental, uma forma de gestão transnacional do planeta, acima do nível estado-nação. A governança global é uma proposta que leva em conta as limitações das fronteiras nacionais num mundo em que as mudanças não encontram barreiras físicas e fogem à compreensão dos atuais mecanismos governantes. De acordo com Giddens (2012, p. 117), à luz desse déficit de governo apontado na encíclica - a governança global propõe a abordagem conjunta de questões que atingem o planeta de modo geral. Assim, como a maioria dos problemas incide acima do nível dos países individuais, argumenta-se que as soluções também se situam no nível transnacional.

Considerando que a preocupação ambiental não se restringe a um só espaço, a um só país, a uma só organização ou a uma só pessoa, Conte et. al (2017, p. 65-66) afirmam que o Direito desponta como uma forma de instrumentalizar e concretizar a proteção ao meio ambiente, seja em uma atuação preventiva, seja em uma perspectiva punitiva. Os autores propõem uma reflexão sobre a responsabilidade universal e solidária dos Estados para a concretização do direito ao meio ambiente ecologicamente equilibrado e enfatizam a necessidade de criação e real observância dos tratados e convenções internacionais em matéria ambiental, bem como de efetiva cooperação jurídica internacional nesta área.

Ainda que expressando a orientação de uma religião especifica, Laudato Si despertou grande visibilidade mundial, especialmente considerando a popularidade do papa Francisco, que vem se revelando um líder em âmbito global (COSTA, 2015, p. 24-25). Pesquisas realizadas nos Estados Unidos (MAIBACH et al., 2015; LI et al., 2016; SCHULDT et al., 
2017) analisaram a percepção das pessoas sobre as mudanças climáticas após a publicação da encíclica

De acordo com Schuldt et al. (2017, p. 167), os impactos foram mais expressivos entre os entrevistados que tinham conhecimento prévio dos pontos de vista do sumo pontífice sobre o assunto. Os pesquisadores concluem que as descobertas confirmam a influência que o Vaticano exerce na formação da opinião pública, o que neste caso oferece perspectivas alvissareiras para o enfrentamento das desigualdades globais que ameaçam a proteção ambiental.

Para Santos (2016, p. 154), uma das possibilidades de solução da crise ambiental é o diálogo, vislumbrado em Laudato Si', entre o ensino religioso e a educação ambiental, com o intuito de criar um espaço mais solidário, mais místico e ético entre os seres humanos e entre a humanidade e o os diversos ecossistemas que povoam a Terra. O desenvolvimento de uma sociedade de consumo ecologicamente sustentável poderá, assim, restituir o sentimento da dignidade humana, levando o ser humano a uma maior profundidade existencial, possibilitando-lhe perceber que vale a pena a sua passagem por este mundo (SERRAGLIO; EFING, 2016, p. 246-247).

\section{DO DIREITO HUMANO AO DIREITO DA NATUREZA}

Para Gilardi (2016, p. 10), a encíclica papal afirma explicitamente que a solução dos problemas globais requer uma mudança de valores, que se desloca dos valores antropocêntricos para os valores ecocêntricos: "É uma visão de mundo que reconhece o valor inerente da vida não humana, onde todo o mundo e todas as coisas estão interconectadas. Este princípio de interconexão é a base da cosmovisão dos povos originários”.

Do mesmo modo, o Observatório do Clima (2015) vê uma inovação teológica no texto do papa Francisco, ao colocar o homem como parte da natureza, não como algo separado dela: “A mensagem central da encíclica [...] é uma frase repetida três vezes [...]: tudo está conectado. O ser humano não está dissociado da Terra ou da natureza, eles são partes de um mesmo todo. Portanto, destruir a natureza equivale a destruir o homem". O papa chama esse raciocínio de "ecologia integral".

Por sua vez, Boff (2015) opina que Laudato $\mathrm{Si}^{\prime}$ coloca o ser humano em relação com os seres não humanos. Ele chama a encíclica de "carta magna" da ecologia integral (portanto, que vai além da ambiental), paradigma que segundo o autor constitui uma inovação entre os documentos do pontificado católico. O teólogo sublinha que a circular define o ser humano 
como Terra, pressuposto que estabelece uma relação e uma interdependência entre todos os seres: "Se é verdade que tudo está em relação, então nós, seres humanos, somos unidos como irmãos e irmãs e nos unimos com terno afeto ao irmão sol, à irmã lua, ao irmão rio e à mãe Terra", diz Boff, parafraseando um dos tópicos de Laudato Si'.

Portanto, se poderia inferir que no texto da encíclica está implícito que o direito do homem constitui do mesmo modo o direito dos demais. Tal primado configura a principal fortaleza da circular papal para a preservação do meio ambiente, a promoção de uma ecologia integral e a melhoria da qualidade de vida.

\section{CONCLUSÃO}

A encíclica papal Laudato Si' se insere nos debates sobre desenvolvimento sustentável, promovendo uma reflexão que extrapola os limites da Igreja Católica, projetando a figura da instituição no debate público sobre o tema. A chamada Carta Verde, firmada pelo papa Francisco, critica os padrões de produção e de consumo da sociedade global e faz um apelo à mudança de comportamento de cristãos e não cristãos.

Nesse contexto, o presente trabalho se propôs a analisar a encíclica Laudato Si' e, a partir daí, estabelecer relações entre a circular papal e os princípios do Direito Ambiental, ponderando suas contribuições para a preservação do meio ambiente e a promoção da qualidade de vida. Autores como Machado (2009), Beltrão (2011), Fiorillo (2011), Silveira (2012) e Sirvinskas (2013) serviram de referência para a constituição do marco teórico da pesquisa. Desde uma perspectiva metodológica, a investigação se estruturou em torno da técnica da análise de conteúdo, da qual Bardin (1977) é o principal expoente.

A realização deste trabalho revelou que as 10 palavras com a maior frequência de ocorrências no texto da encíclica são: Deus (que aparece 158 vezes), mundo (147), vida (137), humano (118), ambiente (92), poder (83), desenvolvimento (79), terra (79), natureza (75) e social (71). Agrupando-se as palavras de acordo com as categorias, se constatou que os princípios do direito ambiental mais vezes aludidos em Laudato Si' são o desenvolvimento sustentado e o direito humano à qualidade de vida. Por outro lado, os princípios com o menor número de referências são o poluidor pagador, a precaução e a prevenção.

Tais resultados indicam que o documento pontifício parte dos princípios de amplitude mais geral em direção aos princípios de aplicação particular ou disciplinar (como é o caso da dimensão relacionado ao poluidor-pagador, por exemplo). A constatação revela o caráter 
universal da mensagem do papa, que não se dirige apenas aos católicos, mas a sociedade como um todo.

Laudato $S i$ ' oferece uma série de contribuições ao debate sobre a preservação do meio ambiente e a promoção da qualidade de vida, as quais são apontadas em estudos anteriores e confirmadas na presente pesquisa:

- A relação do ser humano com o meio ambiente constitui um pressuposto indissociável da concepção universal dos direitos humanos.

- O compromisso com a ecologia integral, que contempla as dimensões ambiental, econômica, cultural e humana, demanda responsabilidade ética, social, política, jurídica e econômica.

- A reversão das atuais tendências de esgotamento dos recursos da Terra demanda um novo modelo de desenvolvimento, que passa pela mudança no "estilo de vida" e nos padrões de comportamento.

- A governança ambiental supõe a reflexão sobre uma gestão transnacional do planeta, acima do nível estado-nação.

A superação da perspectiva antropocêntrica pelos valores ecocêntricos e o reconhecimento do valor inerente da vida não humana constituem alguns avanços e inovações da encíclica papal. Tais pressupostos estabelecem uma relação de interdependência entre todos os seres.

O pano de fundo desse debate é a contribuição do Direito para instrumentalizar e concretizar a proteção ao meio ambiente. A constatação serve de estímulo para a realização de futuras investigações na área, as quais poderiam associar a análise da circular papal ao diálogo com outros documentos da Igreja Católica ou com textos originários de outras religiões.

\section{REFERÊNCIAS}

AQUINO, Felipe. Quais os documentos o Papa usa e qual a diferença entre eles? (2016). Disponível em: <http://cleofas.com.br/quais-os-documentos-que-o-papa-usa-e-qual-adiferenca-entre-eles/>. Acesso em: 20 set. 2017.

A SANTA SÉ. Encíclicas dos Sumos Pontífices (s/d). Disponível em <http://www.vatican.va/offices/encyclicals_list_po.html\#M>. Acesso em: 20 set. 2017.

A
$<$ SANtp://w2.vatican.va/content/francesco/pt/encyclicals/documents/papa-

francesco_20150524_enciclica-laudato-si.html>. Acesso em: 4 set. 2017.

BARDIN, Laurence. Análise de conteúdo. Lisboa: Edições 70, 1977. 
BARRETO, Leandro de M.; MACHADO, Paulo A. L. A construção do diálogo e da solidariedade e a proteção do bem ambiental e da natureza na concepção universal do humano, a partir de uma leitura da encíclica Laudato $\mathrm{Si}^{\prime}$. Veredas do Direito, v. 13, n. 26, p. 319-336, 2016.

BELTRÃO, Antônio F. G. Direito ambiental. São Paulo: Método, 2011.

BOFF, Leonardo. A Carta Magna da ecologia integral: grito da Terra-grito dos pobres. Disponível em: <http://leonardoboff.wordpress.com/2015/06/18/a-carta-magna-da-ecologiaintegral-grito-da-terra-grito-dos-pobres/>. Acesso em: 10 nov. 2017.

BRASIL. Presidência da República. Casa Civil. Subchefia para Assuntos Jurídicos. Constituição da República Federativa do Brasil de 1988. Disponível em: <http://www.planalto.gov.br/ccivil_03/constituicao/constituicaocompilado.htm>. Acesso em: 4 set. 2017.

COELHO, Saulo O. P.; MELLO, Rodrigo A. C. A sustentabilidade como um direito fundamental à concretização da dignidade da pessoa humana e a necessidade de interdisciplinaridade do Direito. Veredas do Direito, v. 8, n. 15, p. 9-24, 2011.

COLOMBO, O princípio da precaução no Direito Ambiental. Revista Eletrônica do Mestrado em Educação Ambiental, v. 14, p. 122-131, 2005.

CONTE, Christiany P. et al. A Encíclica Laudato $\mathrm{Si}^{\prime}$ e os instrumentos jurídicos internacionais de proteção ao meio ambiente. Fé e Cultura, v. 2, n. 1, p. 59-66, 2017.

COSTA, M. A Laudato Si': Um novo, necessário e aprofundado olhar sobre a crise socioambiental na sociedade contemporânea. Fides, v. 6, n. 2, s/p., 2015.

ECCLESIA. Vaticano: Francisco assina $298^{\mathrm{a}}$ encíclica na história da Igreja (2015). Disponível em: <http://www.agencia.ecclesia.pt/noticias/vaticano/vaticano-francisco-assina298-enciclica-na-historia-da-igreja/>. Acesso em: 20 set. 2017.

ESTADÃO. Bento XVI escreveu $1^{\mathbf{a}}$ encíclica de Francisco (2013). Disponível em: $<$ http://www.estadao.com.br/noticias/geral,bento-xvi-escreveu-1-enciclica-defrancisco,1050805>. Acesso em: 20 set. 2017.

FIORILLO, Celso A. P. Curso de direito ambiental brasileiro. São Paulo: Saraiva, 2011.

GIDDENS, Anthony. Sociologia. Porto Alegre: Penso, 2012.

GILARDI, Rubén. La encíclica Laudato Si’ y el modelo de desarrollo. América Latina en Movimiento, n. 515, p. 8-10, 2016.

KOLMES, Steven A.Environmental Policy Choices: The Importance of the Preferential Option for the Poor in Laudato si'. Environment, v. 58, p. 14-17, 2016. 
LEAL, Rodrigo J. Água, direito humano fundamental e sua proteção penal no ordenamento jurídico brasileiro: Das ordenações medievais do reino à normas de controle dos crimes ambientais. Revista Jurídica, v. 19, n. 38, p. 161 - 194, 2015.

LI, Nan et al. Cross-Pressuring Conservative Catholics? Effects of Pope Francis' Encyclical on the U.S. public Opinion on Climate Change. Climate Change, v. 139, n. 3-4, p. 367-380, 2016.

MACHADO, Paulo A. L. Direito ambiental brasileiro. São Paulo: Malheiros, 2009.

MAIBACH, Edward. The Francis Effect: How Pope Francis Changed the Conversation about Global Warming. Fairfax: George Mason University and Yale University, George Mason University Center for Climate Change Communication, 2015.

NATIONAL CATHOLIC REPORTER. A readers' guide to Laudato Si' (2015). Disponível em: 〈http://www.ncronline.org/blogs/faith-and-justice/readers-guide-laudato-si >. Acesso em: 06 nov. 2017.

OBSERVATÓRIO DO CLIMA. Entenda ponto a ponto a encíclica Laudato Si', do papa Francisco. Disponível em: <http://www.observatoriodoclima.eco.br/a-enciclica-de-franciscoponto-a-ponto/>. Acesso em: 10 nov. 2017.

POU-AMÉRIGO, Maria-José. Framing 'Green Pope' Francis: Newspaper coverage of Encyclical Laudato Si' in the United States and the United Kingdom. Church, Communication and Culture, v. 3, n. 2, p. 136-151, 2018.

RÁDIO VATICANO. Laudato si': Um "guia" para a leitura da encíclica (2015). Disponível em:

$<$ http://pt.radiovaticana.va/news/2015/06/18/laudato_si_um_guia_para_os_jornalistas/115232 2>. Acesso em 06 nov. 2017.

REIS, Émilien V. B.; BIZAWU, Kiwonghi. A encíclica Laudato Si' à luz do Direito Internacional do Meio Ambiente. Veredas do Direito, v. 12, n. 23, p. 29-65, 2015.

SANTOS, Ivanaldo. Ensino religioso e a questão ambiental: A perspectiva da Luadato Si' do Papa Francisco. Contemplação, n. 13, p. 139-156, 2016.

SCHULDT, Jonathon et al. Brief exposure to Pope Francis heightens moral beliefs about climate change. Climatic Change, v. 141, p. 167-177, 2017.

SERRAGLIO, Diogo A.; EFING, Antônio C. O direito do consumo voltado à sustentabilidade: Uma análise a partir da carta encíclica Laudato Si' sobre o cuidado da casa comum. Revista de Direito Econômico Socioambiental, v. 7, n. 1, p. 220-249, 2016.

SILVEIRA, Fabrício B. Legislação ambiental: livro didático. Palhoça: Unisul Virtual, 2012.

SIRVINSKAS, Luís P. Manual de direito ambiental. São Paulo: Saraiva, 2013. 
STEFANIAK, Jeaneth N., STEFANIAK, João L. A ecologia crítica num diálogo com a ecologia integral da encíclica papal Laudato $\mathrm{Si}^{\prime}$ cuidando da casa comum. Revista de Direito e Sustentabilidade, v. 1, n. 2, p. 119-138, 2015.

THE VATICAN ARCHIVE. Laudato Si' (2015). Disponível em: <http://www.youtube.com/watch?t=13\&v=1tYdOIqvpqg>. Acesso em: 06 nov. 2017.

VATICAN INSIDER. L'enciclica di Francesco: "La terra è ferita, serve una conversione ecológica" (2015). Disponível em: http://www.lastampa.it/2015/06/18/vaticaninsider/ita/vaticano/lenciclica-di-francesco-la-terraferita-serve-una-conversione-ecologica-rxIbZ7m3nAyoRdqi1giWuL/pagina.html. Acesso em: 01 nov. 2017.

VILLAS BOAS, Regina V.; NASCIMENTO, Grasiele A. F. Diálogos entre o direito, a natureza e a poesia nos versos de Cora Coralina. Anais do IV Colóquio Internacional de Direito e Literatura, p. 244-268, 2016. 